at the last observation had so closely approached the edge that it was scarcely, if at all, visible, and the entire disc might then be said to appear free from spots of any kind. On March 23 the sun remained altogether clouded. At night, however, the sky cleared, and I had a good view of the occultation of Kappa Geminorum. The disappearance was, as usual, instantaneous, but immediately after it a delicate ray seemed to shoot out from the place of the star in a direction perpendicular to the edge of the moon, and the appearance lasted about eight seconds.

Milbrook, Tuam, March 24

J. BIRMINGHAM

\title{
a Centauri
}

AT the meeting of the Royal Astronomical Society December $8,1876, \mathrm{Mr}$. Marth asked for measures of this binary.

As the star never reaches more than $\mathrm{II}^{\circ}$ above my horizon, the definition must always be imperfect; but the following measures taken on the morning of February 22 appear consistent, and may be useful until better results are obtained from the southern hemisphere :-

Epoch $1877^{\circ} \times 4$.$$
\begin{aligned}
& 2 \\
& 3 \\
& 4
\end{aligned}
$$$$
\text { Mean }
$$

$$
\text { Distance. }
$$

$$
\begin{aligned}
& 3 \cdot 4 \\
& 3 \cdot 1 \\
& 3 \cdot x \\
& 3 \cdot 7 \\
& \hline 3 \cdot 3
\end{aligned}
$$$$
\begin{aligned}
& \\
& \ldots \\
& \cdots \\
& \cdots \\
& \cdots
\end{aligned}
$$

Position.

$64^{\circ} \circ$

64.5

$64 \cdot 3$

$64 \cdot 7$

$64 \cdot 4$

The component stars are of about the first and second magnitudes, and their colour is yellow. Power employed, 240; definition very bad.

Jamaica MaxwrLl Hali

\section{The Boomerang:}

Wins you allow me to add my experience of the use of this weapon to that furnished by your other correspondents? My experience is mainly confined to the natives about the Condamine and its affluents, where I was frequently in company with natives for about a year. They had two weapons-one large, for war, the other small, for game. I should think the weapon is seldom thrown in war, since most of their contests (such as they are)take place in scrubb or forest, where it could not be used to advantage ; but I have seen a native frightfully cut in the abdomen, and was told by a native that he had been struck by a boomerang thrown by the hostile party. I have seen a few of these contests, but never saw the boomerang used in any way. The "waddys" were thrown freely, the spear seldom. The game boomerang is thrown among flights of ducks, and also parrots when congregated on the trees and gathering nectar from their flowers, and with marked effect. This I have seen several times. There are two ways of throwing the weapon, which, as I could throw it well at one time, I will endeavour to describe. It is grasped quite at the end by the right hand and raised above the head, the elbow being bent, the weapon assuming a position with its convex edge downwards on a nearly horizontal line at right angles to the intended line of flight. The arm is brought swiftly round from left to right, becoming gradually extended until it reaches a line directly in front of the face, when the weapon is delivered from the now straight arm, with the concave edge towards the line of flight. This is the method of throwing into the air. No dependence can be placed on the return of the weapon within a circle of twenty yards, though it sometimes returns dangerously near the thrower. If it meets with an obstacle it is either stopped and falls dead to the earth, or its course is changed. In either case its peculiar motion is destroyed, as must be obvious. In the other method of throwing the weapon is held in the same way, but delivered nearly on line with the hip, and made to strike the earth about ten yards in front of the thrower, pitching, I believe (though it is not easy to observe), on one of its horns. Thence it ricochets and flies straight away for perhaps seventy or eighty yards, keeping a position of about four feet from the earth, and gradually rising until it is spent. It returns very little if at all. In this way only can it be used for war, since in the other it begins to mount at once, and would soon be above the enemy's head. The weapon is made of various woods, a piece with a slight elbow being selected. It is hardened by baking. The right form is arrived at by trial, as I have seen during the process of manufacture. Those sold to Europeans are the failures. I had to pay a good price for the two I brought home, but they were excellent specimens.
The natives drive ducks. A flight is marked down on a small creek; men are then posted along the bank, others drive the birds towards them, and the boomerangs are thrown as they pass. I do not recollect having seen the weapon used for ground game. These are surrounded and killed with spears and sticks.

ARTHUR NICOLS

\section{Is Meteorology a Science?}

The recent article in NATURE on the Treasury Blue Book relating to meteorology brings into unpleasant prominence the opinion of the eminent astronomer, Sir G. Airy, that meteorology is not a science; and the evidence of the eminent physicist, Sir William Thomson, to the same effect; while a celebrated philosopher in the columns of the Fortnightly Revieze has not long since described meteorology as "a formless registry of facts."

But surely these eminent authorities have hardly realised the great change which has come over the whole aspect of meteorology since the introduction of synoptic charts?

Synoptic meteorology shows that the world is, broadly speaking, covered with shiiting cyclones and anti-cyclones, which have each, subject to local, diurnal, and other variations, a characteristic weather, and physical appearance, and one great problem of meteorology is to explain the observed weather over any area, at any instant, by defining the position of these cyclones and anti-cyclones, It is in fact analogous to that branch of geology which explains the scenery and contours of any country by the position of areas of upheaval, crumbling, and subsequent denu. dation.

But there is another problem for the meteorologist to solve, viz., Given the position of the cyclones and anti-cyclones at any instant, to determine their future course and changes; and this can even now be done in certain cases. As if the geologist, were asked what the future course of the present state of the earth's surface will be, where fresh upheavals or crumblings will occur, and what the corresponding changes in scenery will be? In this case the position of the meteorologist is far in advance of the geologist.

But still another reproach is cast upon meteorology-that the knowledge requisite to issue forecasts cannot be expressed in mathematical formulæ or in simple maxims. Here, too, the analogy of geology may show that neither formulæ nor maxims are necessary to make a science. Just as a number of skilled geologists, from long experience, agree as to the structure of a complicated piece of country, so will a number of meteorologists agree as to the probable course of any series of cyclones or anti-cyclones.

The limits of a letter do not permit me to show why mean values, or harmonic series can never much advance meteorology as a science, if any better argument were needed than their failure after a trial of forty years.

But I think we are justified in saying that, since the introduction of synoptic methods, meteorology is as much a science as geology; that both are pure observational sciences, and that their methods lave much in common, while in some points meteorology is even the further advanced of the two.

2r, Chapel Street, S.W.

RALPH ABERCKOMBY

\section{Atmospheric Currents}

I HOPE you will permit me to reply to Mr. Clement Ley's letter on atmospheric currents in NATURE, vol. xv. p. 450 .

It is certain that the earth's rotation cannot originate any current, but modifies them when originated.

We are agreed as to the cause of the trade-winds. The controversy is as to the questions, Why the trade-winds do not extend to the poles? What is the cause of the counter-trades or west winds between the trade-wind regions and the poles? and what is the cause of the polar depression of the barometer?

The polar depression of the barometer is due to the centrifugal force of the vortex which is constituted by the countertrades as they circulate round the pole from east to west. There is a depression at the centre of every vortex, as any one may see in a wash-basin.

The counter-trades are "the reaction of the trade-winds." The laws of motion make it impossible for the winds to have any effect in either accelerating or retarding the earth's rotation-supposing, what we are safe in taking as proved, that they originate exclusively as the effect of solar heat. The effect of the trade-winds alone, blowing from east to west, would be to 